\title{
Musculoskeletal complaints among professional divers
}

\author{
Fride Flatmo ${ }^{1}$, Marit Grønning ${ }^{2,3}$, Ågot Irgens ${ }^{2}$

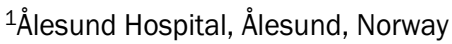 \\ ${ }^{2}$ Department of Occupational Medicine, Haukeland University Hospital, Bergen, Norway \\ ${ }^{3}$ Department of Global Public Health and Primary Care, University of Bergen, Norway
}

\begin{abstract}
Background: Previous publications have indicated a high risk of musculoskeletal complaints among professional divers. This study aims to investigate which factors influence professional divers' risk of musculoskeletal complaints.

Materials and methods: Based on data gathered from a postal questionnaire sent to Norwegian inshore divers in 2011, the prevalence of musculoskeletal complaints, strain injuries and joint pain among divers with different certification levels, work-related tasks and decompression sickness (DCS) experiences were analysed.

Results: The risk of musculoskeletal complaints, strain injuries and joint pain was significantly higher among divers working in the quay/construction industry versus divers not working in this industry, and among divers who had experienced DCS. Likewise, a higher risk was found among divers doing construction, inspection, pipelaying, blasting and welding, other physically demanding work, and working with vibrating and/or rotating tools. Having experienced tingling and/or numbness in fingers after working with vibrating and/or rotating tools or having sick leave due to tendonitis, periosteum inflammation, stretch injuries or sprains caused by diving also increased the risk.

Conclusions: Professional divers working in the quay/construction industry, divers doing tasks with heavy physical demands and divers having experienced DCS are at a higher risk of musculoskeletal complaints than other professional divers.
\end{abstract}

(Int Marit Health 2019; 70, 2: 107-112)

Key words: demanding work, diving, joint pain, musculoskeletal complaints

\section{INTRODUCTION}

Musculoskeletal complaints as part of long term health effects among professional divers have been a topic of research and discussion for the last two decades. A higher prevalence of joint disorders has been found among Unites States (US) military divers compared to nondiving US officers, whereas the non-diving officers were found to have higher hospitalisation rates for stress-related disorders and circulatory disease [1, 2]. In a Norwegian study, former North Sea professional divers reported a reduced health related quality of life compared to the general Norwegian population as measured by the 36-Item Short Form (SF-36). All SF-36 sub-scores, including the subscale rating "bodily pain", were reduced in the diving group. Having experienced decompression sickness (DCS) and high cumulative diving experience contributed to reduced health-related quality of life scores [3]. A study performed in the United Kingdom (UK) found that divers reported more musculoskeletal complaints than offshore workers who did not dive, but these groups did not differ in reported health-related quality of life [4]. Musculoskeletal pain is associated with lower quality of life scores in other workers, such as dockworkers [5]. In the Norwegian population musculoskeletal complaints are highly associated with sick leave [6]. Another study which included a randomly drawn cohort from the general population in Norway where the respondents were in paid work found that highly demanding jobs, neck flexion and awkward lifting appear as the most important predictors of neck/shoulder pain [7].

This study aims to investigate potential risk factors for musculoskeletal complaints in professional divers. 


\section{MATERIALS AND METHODS}

Norwegian inshore divers are certified by the Norwegian Labour Inspection Authority, an occupational safety and health agency of the Ministry of Labour. From 1980 onwards, the Labour Inspection Authority has operated the Norwegian Inshore Diver Registry (Diver Registry) which contains data on all divers with a certificate valid for professional inshore diving. The Norwegian Petroleum Safety Authority manages a separate registry for off-shore divers. Those diving both inshore and offshore are recorded in both registries. By August 2010, 7,079 divers were included in the Diver Registry. Altogether 6,138 of these could be identified with their national identification number, providing their home address.

The study "Diver 2011" used a comprehensive questionnaire which was prepared and sent by mail to all identified divers and a stamped return envelope was enclosed. The questionnaire included questions about diving certification level, work situation, health and diving related issues and was posted during spring 2011 [8].

Altogether 284 questionnaires were excluded due to returned to sender twice or not answered because the receiver told he was a non-diver. Of the remaining, 2,848 (48.7\%) persons completed the questionnaire.

The analyses of musculoskeletal complaints were based on three sets of questions from the questionnaire. Each set were considered positive if the subject had given a positive answer to at least one of the sub-questions, and negative if the subject had given a negative answer to all.

"Have you during the last 12 months had pain and/or stiffness in muscles and joints, lasting for at least three months?":

- Set 1: This set includes all the questions; neck, upper back, lumbar region, shoulder, elbow, wrist/hand, groin, hip, knee and ankle/foot;

- Set 2: Typical strain; neck, upper back and lumbar region;

- Set 3: Typical joints; shoulder, elbow, wrist/hand, groin, hip, knee and ankle/foot.

Certificates are graded according to qualification: Class S is restricted to scientific diving with SCUBA gear to a maximum depth of $30 \mathrm{~m}$. Class $\mathrm{R}$ is restricted to rescue diving to a maximum depth of $30 \mathrm{~m}$. Class 1 requires practical and theoretical training to perform subsea work to a maximum depth of $50 \mathrm{~m}$. Class 2 (closed bell) requires the same training (practical and theoretical) as for Class 1, but in addition the divers are trained and educated in saturation and bell diving. Class 3 requires the same training as Class 1, and in addition practical and theoretical training in specialised subsea work. The qualification range among the certificates are as follows; $2>3>1>\mathrm{R}, \mathrm{S}$.

The divers were categorised depending on mainly working in different industries (Quay/construction, Fish farming, Collecting shells, Offshore, Rescue, Photography, Instructor,
Research) and doing certain tasks often (positive answer) or seldom/never (negative answer). Potential risk factors like physically demanding work, working with vibrating and/or rotating tools, having experienced tingling and/or numbness in fingers after working with vibrating and/or rotating tools and if the diver had had any sick leave because of tendonitis, periosteum inflammation, stretch injuries or sprains caused by diving were analysed.

When analysing the risk of musculoskeletal complaints by the divers' level of qualification, divers having restricted certification (R and $S$ certificates) were used as references. Divers with reported DCS, with or without paresis, were compared to divers not having experienced DCS or DCS with paresis, respectively. When analysing the various industries and tasks, and the additional risk factors, divers not having worked in the industry, doing the task or have the risk factor under study were used as references.

The divers included in the study had given their written consent and the study was approved by the Regional committee for medical and health research ethics (REC WEST 2010; 02529).

\section{STATISTICAL METHODS}

The descriptive statistics are presented as graphs and tables. Quartiles of age was defined as Q1 < 37 years, Q2 = 38-45 years, Q3 = 46-53 years and Q4 > 54 years. Relative risks (RR) of musculoskeletal complaints, strain injury and joint pain were analysed by Generalised Linear Models with binomial distribution and log link. Both crude and adjusted (age, gender, total number of dives and at least one episode of DCS) RR with 95\% confidence intervals (Cl) were reported. All statistical analyses were performed by IBM SPSS version 22 [IBM Corp. Released 2013. IBM SPSS Statistics for Windows, Version 22.0. Armonk, NY: IBM Corp].

\section{RESULTS}

The study included 2,663 males and 185 females. The median age was 45.0 and 38.0 years, respectively.

Quay/construction and offshore divers reported more often working in: construction work (76.8\% and 69.1\%), blasting (34.3\% and $36.4 \%$ ), welding (23.5\% and $31.6 \%$ ), physically demanding work (69.6\% and $78.5 \%)$, work with vibrating/rotating tools $(80.1 \%$ and $86.2 \%)$ than divers in other diving industries (i.e. fish farming: 46.7\%, 14.6\%, $13.0 \%, 55.5 \%, 71.8 \%)$.

The prevalence of musculoskeletal complaints increased (Fig. 1) with increasing age. Mean number of dives performed was 1066.3. Divers having performed 1,255 dives or more (the upper quartile) reported more musculoskeletal complaints than those having performed less dives. Having experienced DCS was reported by 469 (16.5\%) of the responders. 

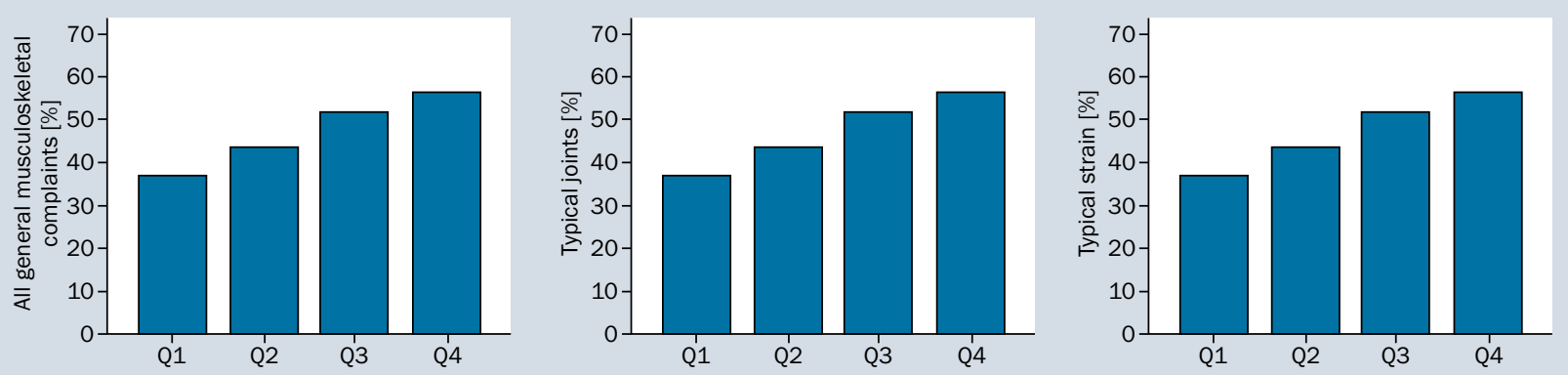

Figure 1. Reported musculoskeletal complaints in age quartiles

Table 1. Musculoskeletal complaints reported in professional divers with different diving certificate

\begin{tabular}{|c|c|c|c|c|c|c|}
\hline & Certification level & N (\%) & Crude RR & $95 \% \mathrm{Cl}$ & Adjusted RR* & $95 \% \mathrm{Cl}$ \\
\hline \multirow[t]{4}{*}{ All } & $\mathrm{R}$ and $\mathrm{S}$ (reference) & 445 (40.9) & 1 & & 1 & \\
\hline & 1 & $364(53.4)$ & 1.31 & $1.18-1.44$ & 1.11 & $0.96-1.27$ \\
\hline & 3 & $101(59.8)$ & 1.46 & $1.27-1.69$ & 1.20 & $1.04-1.38$ \\
\hline & 2 & $144(54.8)$ & 1.34 & $1.17-1.53$ & 1.13 & $1.02-1.26$ \\
\hline \multirow[t]{4}{*}{ Typical strain injuries } & $\mathrm{R}$ and $\mathrm{S}$ (reference) & 311 (28.1) & 1 & & 1 & \\
\hline & 1 & $272(38.6)$ & 1.37 & $1.20-1.57$ & 1.18 & $1.03-1.35$ \\
\hline & 3 & $73(42.7)$ & 1.52 & $1.25-1.85$ & 1.13 & $0.92-1.39$ \\
\hline & 2 & $116(43.1)$ & 1.53 & $1.30-1.81$ & 1.18 & $0.99-1.41$ \\
\hline \multirow[t]{4}{*}{ Typical joint pains } & $\mathrm{R}$ and $\mathrm{S}$ (reference) & 345 (31.2) & 1 & & 1 & \\
\hline & 1 & 305 (43.3) & 1.39 & $1.23-1.57$ & 1.20 & $1.06-1.36$ \\
\hline & 3 & $93(54.4)$ & 1.74 & $1.48-2.05$ & 1.30 & $1.10-1.54$ \\
\hline & 2 & $121(45.0)$ & 1.44 & $1.23-1.69$ & 1.13 & $0.96-1.34$ \\
\hline
\end{tabular}

*Adjusted for age, gender, total number of dives and decompression sickness; $\mathrm{Cl}$ - confidence interval; RR - relative risk

\section{MUSCULOSKELETAL COMPLAINTS - GENDER}

Male and females reported similar frequency of 'all musculoskeletal complaints' ( $46.9 \%$ vs. $45.9 \%)$, strain injuries (34.7\% vs. $33.0 \%)$, and joint pains (38.6\% vs. $35.1 \%)$.

\section{MUSCULOSKELETAL COMPLAINTS - CERTIFICATION LEVELS}

After adjustments, divers holding certificate level 3 and 2 had increased risk of musculoskeletal complaints compared to divers holding restricted certificates (R or S). Divers holding certificate level 1 had higher risk of typical strain injuries and divers holding certificate level 1 and 3 had a higher risk of typical joint pain (Table 1).

\section{MUSCULOSKELETAL COMPLAINTS - DCS}

After adjustments the risks of musculoskeletal complaints, strain injuries and joint pain were higher among divers having experienced DCS with and without paresis (Table 2).

\section{MUSCULOSKELETAL COMPLAINTS - ALL}

Working in the quay/construction industry was the only industry associated with a significantly higher risk of musculoskeletal complaints after adjustment. All tasks (construction, inspection, maintenance, laying pipes, blasting, welding) and the potential risk factors (physically demanding work, working with vibrating and/or rotating tools, having experienced tingling and/or numbness in fingers after working with vibrating and/or rotating tools and if the diver had had any sick leave because of tendonitis, periosteum inflammation, stretch injuries or sprains caused by diving) were associated with a significantly higher risk of musculoskeletal complaints after adjustment.

\section{MUSCULOSKELETAL COMPLAINTS - STRAIN}

Working in the quay/construction industry was the only industry associated with a significantly higher risk of strain injury after adjustment. All tasks except pipelaying, and all the additional risk factors (physically demanding work, 
Table 2. Musculoskeletal complaints reported in professional divers having experienced decompression sickness (DCS)

\begin{tabular}{|c|c|c|c|c|c|c|c|}
\hline & & & $\mathrm{N}(\%)$ & Crude RR & $\mathrm{Cl}$ & Adjusted RR* & $\mathrm{Cl}$ \\
\hline \multirow[t]{4}{*}{ All } & DCS & No & $1007(44.6)$ & 1 & & 1 & \\
\hline & & Yes & 307 (65.9) & 1.47 & $1.36-1.60$ & 1.26 & $1.15-1.37$ \\
\hline & DCS with paresis & No & $546(49.5)$ & 1 & & 1 & \\
\hline & & Yes & $94(76.4)$ & 1.55 & $1.38-1.73$ & 1.33 & $1.18-1.51$ \\
\hline \multirow[t]{4}{*}{ Typical strain injuries } & DCS & No & 730 (31.9) & 1 & & 1 & \\
\hline & & Yes & $239(51.0)$ & 1.60 & $1.43-1.78$ & 1.31 & $1.16-1.96$ \\
\hline & DCS with paresis & No & $404(36.3)$ & 1 & & 1 & \\
\hline & & Yes & $85(68.5)$ & 1.89 & $1.64-2.18$ & 1.62 & $1.39-1.89$ \\
\hline \multirow[t]{4}{*}{ Typical joint pains } & DCS & No & $811(35.5)$ & 1 & & 1 & \\
\hline & & Yes & $265(56.5)$ & 1.59 & $1.45-1.75$ & 1.29 & $1.16-1.44$ \\
\hline & DCS with paresis & No & $428(38.5)$ & 1 & & 1 & \\
\hline & & Yes & $85(68.5)$ & 1.78 & $1.55-2.05$ & 1.46 & $1.26-1.69$ \\
\hline
\end{tabular}

*Adjusted for age, gender and total number of dives; $\mathrm{Cl}$ - confidence interval; RR - relative risk

working with vibrating and/or rotating tools, having experienced tingling and/or numbness in fingers after working with vibrating and/or rotating tools and if the diver had had any sick leave because of tendonitis, periosteum inflammation, stretch injuries or sprains caused by diving) were, after adjustment, associated with a significantly higher risk of strain injuries than the referents.

\section{MUSCULOSKELETAL COMPLAINTS - JOINTS}

Working in the quay/construction industry, fish farming and rescue industry, all tasks listed and all the listed additional risk factors were, after adjustment, associated with a significantly higher risk of joint pain.

Additional statistical analysis was done adjusting for age, gender, total number of dives and DCS with paresis. When analysed with this adjustment, the listed additional potential risk factors still were associated with significantly higher risk of all musculoskeletal complaints, strain injuries and joint pain. Also, with this adjustment, divers working in the quay/construction, and doing industry-related tasks (construction, inspection, maintenance, blasting and welding) had higher risk of strain injuries. The subgroup of these divers who also were engaged in pipelaying had a higher risk of joint pain. Divers working as instructors were found to have a significantly lower risk of joint pain after doing this second adjustment. However, the statistic strength of the analysis was weak after doing this second adjustment, and these results are not included in this study.

\section{DISCUSSION}

In our study, divers with higher certification levels and the subgroup who worked in the quay/construction indus- try tended to report musculoskeletal pain, joint pain and strain injuries equally or more often than divers holding a restricted certificate, and especially if they had experienced DCS. The prevalence of these complaints was higher among divers working in the quay/construction industry, and among divers doing demanding industry related tasks. Having experienced tingling and/or numbness in fingers after working with vibrating and/or rotating tools or having sick leave due to tendonitis, periosteum inflammation, stretch injuries or sprains caused by diving also increased risk of musculoskeletal complaints.

This cross-sectional study includes approximately half of the professional inshore diving population in Norway between 1980 and 2011, including both professional divers and divers who mostly dive recreationally (restricted certificates); divers with a great variety in total numbers of dives performed. The questionnaire used included questions related to a variety of diving-related issues and health issues. This gave us a good overview of the divers' health situation, and gave us an opportunity to look specifically into the various industries in which professional divers are employed, and the tasks they perform, to see whether some of them carry higher risk of musculoskeletal complaints than others. Not all divers responded to all questions.

Many divers have been working in more than one industry [9], but we did not differentiate for this in our study. It is likely that several responders had had musculoskeletal complaints in more than one location [10, 11]. Neither did we differentiate between former and current professional divers. Former professional divers have reported less diving related education, higher number of annual and daily dives, more frequent DCS, loss of consciousness while diving and 
physically demanding dives (diving with much variation in depth, depths deeper than $30 \mathrm{~m}$, bottom time giving more than 15 min decompression time, strenuous dives or being cold/freezing during decompression) [8]. This might have influenced our result since loss of consciousness while diving is shown to have a negative impact on health-related quality of life in former North Sea professional divers [12], and musculoskeletal symptoms are increased for workers in cold environments [13].

The prevalence of musculoskeletal complaints increases with increasing age in the general population [14], and ageing is found to increase the risk of injury during recreational diving and may decrease the divers' recovery potential [15]. In our study, divers with higher age and divers with a high total number of dives had a higher prevalence of musculoskeletal complaints. In the Hordaland Health Studies (HUSK), women were found to have higher risk of musculoskeletal complaints [16]. We did not find a difference in musculoskeletal complaints among male and female divers in our study, which may indicate that female divers are in extraordinary good health or it might be due to the low number of female divers in our data. Having had DCS during the diving career was associated with reduced health related-quality of life (SF-36) subscale 'bodily pain', both compared to the general Norwegian population and to the Norwegian divers not having experienced DCS [3]. In our data, divers having experienced DCS reported musculoskeletal complaints more often.

Overall, $48.5 \%$ of the divers in this study reported to have had musculoskeletal complaints lasting at least 3 months during the past 12 months. This prevalence is comparable to the ones found in the Norwegian general population in the Nord-Trøndelag Health Study (HUNT) (51\%) [17] and in the HUSK Study (39\% of males and $49 \%$ of females) [11]. In a previous UK study, a significantly higher proportion of divers reported musculoskeletal symptoms compared to offshore workers ( $41 \%$ vs. $34 \%$ ) [18]. However, the divers doing the listed tasks were found to have a significantly higher risk of these complaints and the risk tend to be higher than the risk found in the general Norwegian population.

Heavy physical demands at work are associated with musculoskeletal complaints [19-22], which were also shown in our study. Also, psychosocial factors at the workplace are associated with musculoskeletal disorders, in particular when combined with heavy physical demands [23-25]. Psychosocial stress at work was, however, not a part of our study.

Our finding suggests divers having worked with vibration and/or rotating tools are at an increased risk of musculoskeletal complaints, as is also shown for other workers using such equipment [26].

Musculoskeletal complaints are the dominating group of diagnosis leading to sick leave in Norway, constituting
$40-50 \%$ of total annual cases [6]. Longstanding (> 3 months) symptoms is an independent risk factor shown to double the risk of sick leave [16], and the presence of symptoms can predict sick leave in the following 12 months [27]. Sick leave was strongly associated with musculoskeletal complaints among divers in our study.

In our study, divers working in the quay and construction industry had a higher risk of musculoskeletal complaints, strain injuries and joint pain than other divers, and in general, all the tasks listed also contributed to an increased risk. Tasks like construction, blasting, welding, pipelaying, maintenance are often performed in the quay/construction industry. Construction workers are known to have increased risk of occupational ill health both globally and in Europe [28], and higher risk of musculoskeletal disorders are shown in Germany [29] and in the UK [30,31]. Welders have an increased risk of musculoskeletal complaints related to heavy physical demands at work $[21,30]$. This is also shown to be the case for professional divers working as welders and divers having experienced work related accidents [4] which is similar to our findings.

\section{CONCLUSIONS}

Professional divers working in industries with heavy physical demands, such as the quay/construction industry, are at a higher risk of musculoskeletal complaints than professional divers working in other industries. This risk is shared by workers with high physical demands working on land. The data must be interpreted with caution since multiple risk factors, including psychosocial factors at the work place, are likely to be involved, and this study is not designed to show causality. Further research is needed to be done on this issue.

\section{REFERENCES}

1. HoibergA, Blood C. Health risks of diving among U.S. Navy officers. Undersea Biomed Res. 1986; 13(2): 237-245, indexed in Pubmed: 3727185.

2. Hoiberg A, Blood C. Age-specific morbidity and mortality rates among U.S. Navy enlisted divers and controls. Undersea Biomed Res. 1985; 12(2): 191-203, indexed in Pubmed: 4071846.

3. Irgens A, Grønning M, Troland K, et al. Reduced health-related quality of life in former North Sea divers is associated with decompression sickness. Occup Med (Lond). 2007; 57(5): 349-354, doi: 10.1093/ occmed/kqm032, indexed in Pubmed: 17548867.

4. Macdiarmid Jl, Ross JA, Taylor CL, Watt SJ, Adie W et al. Co-ordinated investigation into the possible long term health effects of diving at work: Examination of the long term health impact of diving: The ELTHI diving study. ISBN 0717628485 j. http://www.hse.gov.uk/ research/rrpdf/rr230.pdf (November 2017, date last accessed).

5. de Carvalho MP, Schmidt LG, Soares MC. Musculoskeletal disorders and their influence on the quality of life of the dockworker: A cross-sectional study. Work. 2016; 53(4): 805-812, doi: 10.3233/WOR-162249, indexed in Pubmed: 26890589.

6. Ose SO, Jensberg H, Reinertsen RE, et al. Sykefravær. Kunnskapsstatus og problemstillinger. [Sick leave, knowledge status and issues] 
SINTEF-rapport A325. Trondheim: SINTEF Helse, 2006. ISBN: 82-312-0000-2 978-82-312-0000-0 . https://www.regjeringen. no/globalassets/upload/aid/kampanjer/arbeidslivsforum/ dokumenter/motedokumenter/sintef_-rapport_sykefraver.pdf . (November 2017, date last accessed).

7. Sterud T, Johannessen HA, Tynes T. Work-related psychosocial and mechanical risk factors for neck/shoulder pain: a 3-year follow-up study of the general working population in Norway. Int Arch Occup Environ Health. 2014; 87(5): 471-481, doi: 10.1007/s00420013-0886-5, indexed in Pubmed: 23708752.

8. Irgens Å, Grønning M, Thorsen E, Troland K. Dykkerstudien 2011 [The Norwegian diver 2011]. Bergen ISBN: 978-82-998162-1-2 . https://helse-bergen.no/seksjon/Nasjonal\%20behandlingstjeneste\%20for\%20yrkesmedisinsk\%20utredning\%20av\%20 yrkesdykkere/Documents/Dykkerstudien2011.pdf (November 2017, date last accessed).

9. Report: Technical report number 1; `Likheter og ulikheter mellom dykkere I oppdrettsn ringen og kai og anleggsdykkere. [Similarities and differences between divers In aquaculture and quay/construction divers]. :https://helse-bergen.no/seksjon/Nasjonal\%20behandlingstjeneste\%20for\%20yrkesmedisinsk\%20utredning\%20 av\%20yrkesdykkere/Documents/Teknisk\%20Rapport\%201.pdf (November 2017, date last accessed).

10. Kamaleri Y, Natvig B, Ihlebaek CM, et al. Number of pain sites is associated with demographic, lifestyle, and health-related factors in the general population. Eur J Pain. 2008; 12(6): 742-748, doi: 10.1016/j.ejpain.2007.11.005, indexed in Pubmed: 18160318.

11. Sirnes E, Sødal E, Nurk E, et al. [Occurrence of musculoskeletal complaints in Hordaland]. Tidsskr Nor Laegeforen. 2003; 123(20): 2855-2859, indexed in Pubmed: 14600709.

12. Sundal E, Irgens Å, Troland K, et al. Prevalence and causes of loss of consciousness in former North Sea occupational divers. Int Marit Health. 2013; 64(3): 142-147, indexed in Pubmed: 24072541.

13. Pienimäki T. Cold exposure and musculoskeletal disorders and diseases. A review. Int J Circumpolar Health. 2002; 61(2): 173-182, doi: 10.3402/ijch.v61i2.17450, indexed in Pubmed: 12078965.

14. Ihlebaek C, Brage S, Natvig B, et al. [Occurrence of musculoskeletal disorders in Norway]. Tidsskr Nor Laegeforen. 2010; 130(23): 2365-2368, doi: 10.4045/tidsskr.09.0802, indexed in Pubmed: 21139663.

15. Smerz RW. Age associated risks of recreational scuba diving. Hawaii Med J. 2006; 65(5): 140-1, indexed in Pubmed: 16774142.

16. Andersen I, Frydenberg H, Maeland JG. [Musculoskeletal disease and sick-leave]. Tidsskr Nor Laegeforen. 2009; 129(12): 1210-1213, doi: 10.4045/tidsskr.09.32410, indexed in Pubmed: 19521442.

17. Holth HS, Werpen HK, Zwart JA, et al. Physical inactivity is associated with chronic musculoskeletal complaints 11 years later: results from the Nord-Trøndelag Health Study. BMC Musculoskelet Disord. 2008; 9: 159, doi: 10.1186/1471-2474-9-159, indexed in Pubmed: 19046448.

18. Ross JAS, Macdiarmid JI, Osman LM, et al. Health status of professional divers and offshore oil industry workers. Occup Med (Lond). 2007; 57(4): 254-261, doi: 10.1093/occmed/kqm005, indexed in Pubmed: 17317702.
19. Holmström E, Engholm G. Musculoskeletal disorders in relation to age and occupation in Swedish construction workers. Am J Ind Med. 2003; 44(4): 377-384, doi: 10.1002/ajim.10281, indexed in Pubmed: 14502765.

20. de Zwart BC, Broersen JP, Frings-Dresen MH, et al. Repeated survey on changes in musculoskeletal complaints relative to age and work demands. Occup Environ Med. 1997; 54(11): 793-799, doi: 10.1136/oem.54.11.793, indexed in Pubmed: 9538351.

21. Törner M, Zetterberg C, Andén U, et al. Workload and musculoskeletal problems: a comparison between welders and office clerks (with reference also to fishermen). Ergonomics. 1991; 34(9): 1179-1196, doi: 10.1080/00140139108964854, indexed in Pubmed: 1743177.

22. Boschman JS, van der Molen HF, Sluiter JK, et al. Occupational demands and health effects for bricklayers and construction supervisors: A systematic review. Am J Ind Med. 2011; 54(1): 55-77, doi: 10.1002/ajim.20899, indexed in Pubmed: 20886532.

23. Yassi A. Work-related musculoskeletal disorders. Curr Opin Rheumatol. 2000; 12(2): 124-130, indexed in Pubmed: 10751015.

24. Devereux JJ, Vlachonikolis IG, Buckle PW. Epidemiological study to investigate potential interaction between physical and psychosocial factors at work that may increase the risk of symptoms of musculoskeletal disorder of the neck and upper limb. Occup Environ Med. 2002; 59(4): 269-277, doi: 10.1136/oem.59.4.269, indexed in Pubmed: 11934955.

25. Devereux JJ, Buckle PW, Vlachonikolis IG. Interactions between physical and psychosocial risk factors at work increase the risk of back disorders: an epidemiological approach. Occup Environ Med. 1999; 56(5): 343-353, doi: 10.1136/oem.56.5.343, indexed in Pubmed: 10472310.

26. Stenlund B, Goldie I, Hagberg M, et al. Shoulder tendinitis and its relation to heavy manual work and exposure to vibration. Scand J Work Environ Health. 1993; 19(1): 43-49, indexed in Pubmed: 8465171.

27. Burdorf A, Naaktgeboren B, Post W. Prognostic factors for musculoskeletal sickness absence and return to work among welders and metal workers. Occup Environ Med. 1998; 55(7): 490-495, doi: 10.1136/oem.55.7.490, indexed in Pubmed: 9816384.

28. Watterson A. Global construction health and safety-what works, what does not, and why? Int J Occup Environ Health. 2007; 13(1): 1-4, doi: 10.1179/107735207800245027, indexed in Pubmed: 17427341.

29. Arndt V, Rothenbacher D, Daniel U, et al. Construction work and risk of occupational disability: a ten year follow up of 14,474 male workers. Occup Environ Med. 2005; 62(8): 559-566, doi: 10.1136/ oem.2004.018135, indexed in Pubmed: 16046609.

30. Stocks SJ, Turner S, McNamee R, et al. Occupation and work-related ill-health in UK construction workers. Occup Med (Lond). 2011; 61(6): 407-415, doi: 10.1093/occmed/kqr075, indexed in Pubmed: 21752940.

31. Stocks SJ, McNamee R, Carder M, et al. The incidence of medically reported work-related ill health in the UK construction industry. Occup Environ Med. 2010; 67(8): 574-576, doi: 10.1136/ oem.2009.053595, indexed in Pubmed: 20647381. 